\title{
Increased Soil Fertility in Tea Plantations Leads to Declines in Fungal Diversity and Complexity in Subsoils
}

peng yan ( $\square$ yanpengzn@163.com )

Key Laboratory of Tea Quality and Safety Control, Ministry of Agriculture, Tea Research Institute, Chinese Academy of Agricultural Sciences, Hangzhou, 310008, China

\section{Chen Shen}

Key Laboratory of Tea Quality and Safety Control, Ministry of Agriculture, Tea Research Institute, Chinese Academy of Agricultural Sciences, Hangzhou, 310008, China

\section{Zhenhao Zou}

Key Laboratory of Tea Quality and Safety Control, Ministry of Agriculture, Tea Research Institute, Chinese Academy of Agricultural Sciences, Hangzhou, 310008, China

\section{Lichao Fan}

Key Laboratory of Tea Quality and Safety Control, Ministry of Agriculture, Tea Research Institute, Chinese Academy of Agricultural Sciences, Hangzhou, 310008, China

\section{Xin Li}

Key Laboratory of Tea Quality and Safety Control, Ministry of Agriculture, Tea Research Institute, Chinese Academy of Agricultural Sciences, Hangzhou, 310008, China

\section{Liping Zhang}

Key Laboratory of Tea Quality and Safety Control, Ministry of Agriculture, Tea Research Institute, Chinese Academy of Agricultural Sciences, Hangzhou, 310008, China

\section{Lan Zhang}

Key Laboratory of Tea Quality and Safety Control, Ministry of Agriculture, Tea Research Institute, Chinese Academy of Agricultural Sciences, Hangzhou, 310008, China

\section{Chunwang Dong}

Key Laboratory of Tea Quality and Safety Control, Ministry of Agriculture, Tea Research Institute, Chinese Academy of Agricultural Sciences, Hangzhou, 310008, China

\section{Jianyu Fu}

Key Laboratory of Tea Quality and Safety Control, Ministry of Agriculture, Tea Research Institute, Chinese Academy of Agricultural Sciences, Hangzhou, 310008, China

\section{Wenyan Han}

Key Laboratory of Tea Quality and Safety Control, Ministry of Agriculture, Tea Research Institute, Chinese Academy of Agricultural Sciences, Hangzhou, 310008, China

\section{Lingling Shi}


Biogeochemistry of Agroecosystems, Department of Crop Science, University of Göttingen, Göttingen, Germany

\section{Research Article}

Keywords: Community assembly, Fungal functional guilds, Soil fertility, Tea plantation, Vertical soil profile Posted Date: July 24th, 2021

DOl: https://doi.org/10.21203/rs.3.rs-717224/v1

License: (9) This work is licensed under a Creative Commons Attribution 4.0 International License. Read Full License 


\section{Abstract}

Purpose The effects of fertilization of tea plantations on soil quality and the diversity and composition of microbial communities have received increased attention in recent years. Despite their important role as decomposers of organic matter, the responses of soil fungi to fertilization and soil fertility, particularly in subsoils, remain unknown. In this study, the effects of land-use change and fertilization on fungal diversity and function in both of topsoil and subsoils were evaluated.

Methods We sampled soil profiles $(0-60 \mathrm{~cm})$ from tea plantations in southeastern China with low, moderate, and high inputs of mineral and organic fertilizers, as well as a nearby natural (unfertilized) forest. 18s rRNA Illumina sequencing was used to evaluate how soil fertility and land-use impacted fungal diversity and function.

Results Following conversion from forest to tea plantation, soil fungal diversity increased with fertility in topsoil but declined in subsoils, resulting in significant vertical variation in highly fertile soils. The dominant fungal groups shifted from Solicoccozyma and Trichoderma in the forest to Pseudogymnoascus and Umbelopsis in tea plantation soils. Relative abundance of Pseudogymnoascus increased with soil fertility, while Mortierella and opportunistic saprotrophs exhibited the opposite pattern. Fungal network complexity was enhanced in topsoil under increased soil fertility, but decreased in the subsoil, suggesting an increased selective effect along the soil horizon. Land-use changes have altered the dominant fungal groups, particularly in topsoil. Soil fertility not only regulated fungal diversity but also shifted community composition toward that found in the forest. With increased soil fertility, plants have a greater influence on the soil fungal community.

\section{Introduction}

Soil fertility is the inherent capacity of a soil to provide essential nutrients for plant growth in adequate amounts and suitable proportions. As "built-in" soil regulators and catalysts that contribute to recycling nutrients into available inorganic forms, soil microorganisms mediate soil fertility and nutrient uptake processes. Recently, increasing attention has been focused on soil fungi, which link soil processes with nutrient uptake by plants (Tedersoo et al. 2015). However, fungal activity is affected not only by substrate availability but also by soil environmental conditions (e.g., texture, $\mathrm{pH}$, moisture) (Blagodatskaya and Kuzyakov 2008). Previous studies have suggested that fertilization reduces microbial diversity in the topsoil; however, few studies have considered the vertical spatial distribution of microbes in the soil. Different environmental conditions between the topsoil and subsoil result in distinct microbial community structures (Baath and Anderson 2003; Glassman et al. 2017), particularly in the fungal community. However, the effects of the interaction between soil fertility and depth on both the abundance and function of soil microbial communities, and plant-microbe interaction dynamics, throughout the soil profile remain unclear. 
Soil fungi, including saprotrophic and symbiotic fungi (mycorrhizal, pathogenic, and endotrophic), exhibit significant vertical patterning, and are affected by substrate resource availability (McGuire et al. 2013). Saprotrophic fungi are primarily carbon (C) decomposers, and thus occur in the topsoil, where organic matter from plant litter accumulates (Rousk et al. 2009). By contrast, symbiotic fungi occur in subsoils, obtaining $C$ entirely from plant roots, and are directly involved in plant nutrient uptake (Bonfante 2018). The interactions between saprotrophic and symbiotic fungi influence overall fungal community function and plant-soil ecological processes (Baar et al. 1999). Based on physiological differences, fungal species have different requirements with respect to the quality and quantity of $C$ substrates (e.g., labile and recalcitrant $\mathrm{C}$ content, carbon-nitrogen (C-N) ratio), resulting in differential growth responses among taxa to $C$ substrates of varying chemical recalcitrance (Goldfarb et al. 2011). Due to substrate preferences, studies also suggest that soil fertility affects microbial interactions by increasing the dominance of certain groups and reducing network connections (Yadav et al. 2015).

Soil fungal community assemblages are shaped by specific environmental factors, particularly soil water content, $\mathrm{C}-\mathrm{N}$ ratios, and $\mathrm{pH}$, which also affect soil fertility and vary among soil layers (Peigné et al. 2018). Soil water content affects the transportation of fertilizer inputs from surface soils to subsoils as well as the availability of nutrients to plants and soil fungi (Griffin 1963). Carbon enrichment in surface soils increases rates of $\mathrm{N}$ cycling compared to subsoils. Clay content affects fungal growth and enzyme activity (Tedersoo et al. 2014). Soil pH is decreased by chemical fertilizer inputs, and is higher in subsoils than in surface soils (Yan et al. 2018), benefiting fungi that decompose soil organic matter (Tanjang et al. 2009). As with substrate utilization, soil fungal species have distinct ecological niches, and are consequently affected by the interactions between fertility and soil environmental factors.

Most attempts to identify the processes that structure natural communities have focused on conspicuous macroorganisms, whereas those which structure microbial communities remain relatively unknown. Two main theories have emerged to explain these processes: niche theory, which highlights the importance of deterministic processes, and neutral theory, which focuses on stochastic processes (Cira et al. 2018). Environmental stress selects microbes by substrate availability, and species persist according to the availability of their ecological niche (O'Malley 2008). Microbial interactions in turn affect populations via predation, competition, or facilitation (Dumbrell et al. 2010). The balance between selective forces, both extrinsic and intrinsic, shape community composition and function. Soil nutrient availability is considered a key environmental driver and has been shown to shape microbial community assembly and behavior. With increased soil organic inputs, community composition becomes increasingly complex as a result of nutrient limitations (Garcia-Orenes et al. 2016). However, most of these studies focus on surface soils, which are considered hotspots of microbial activity (Lazcano et al. 2013). Little attention has been given to deeper soils, and it is unclear whether fungal communities in deeper soils are shaped by similar assembly processes.

We investigated the community composition of soil fungi along a vertical profile (i.e., soil depths of $0-60$ $\mathrm{cm}$ ) in three tea plantations with different fertilizer input levels, as well as in a nearby forest, and explored changes in the fungal community along the vertical gradient and under different input treatments. We 
hypothesize that soil fungal diversity is positively correlated with fertilizer inputs, with a more pronounced increase in surface soils compared to the subsoils as fertilizer inputs may promote microbial groups that are currently nutrient-limited. In addition, we expect microbial composition to change, with saprotrophic microbes increasing as fertilizer inputs select for certain fungal groups, particularly saprotrophic fungi, that can use labile $\mathrm{C}$ and nutrients. Finally, we hypothesize that fertilizer inputs affect fungal communities directly through changes in soil chemical properties. Fungal diversity and composition may be shaped directly by environmental factors or indirectly through interspecific interactions. These processes were variously affected by fertilizer inputs.

\section{Materials And Methods Study sites}

Study sites were located in Hangzhou City, Zhejiang Province, China. The annual mean temperature at the sites is $17.0^{\circ} \mathrm{C}$, and ranges from $1.7^{\circ} \mathrm{C}$ in January to $33.0^{\circ} \mathrm{C}$ in July. Average annual precipitation is 1553 $\mathrm{mm}$, and about $74 \%$ of total rainfall occurs during the tea growing season, between March and September. To assess the effects of tea cultivation and organic inputs on soil microbial communities, three tea plantations with different fertilizer input levels (low, moderate, and high), as well as the forest adjacent to the tea plantations, were sampled. Sites were located at $120^{\circ} 10 \otimes \mathrm{E}, 30^{\circ} 10 \otimes \mathrm{N}$ and separated by less than $0.5 \mathrm{~km}$.

Rates of mineral $\mathrm{N}$ application were $300 \mathrm{~kg} \mathrm{ha}^{-1}, 600 \mathrm{~kg} \mathrm{ha}^{-1}$, and $900 \mathrm{~kg} \mathrm{ha}^{-1}$ in the low, moderate, and high input plantations, respectively. In addition, organic fertilizer (rape seed cake with $4.6 \% \mathrm{~N}, 0.9 \% \mathrm{P}, 1.2 \%$ $\mathrm{K}$ ) was applied to the low, moderate, and high input plantations at rates of $0 \mathrm{~kg} \mathrm{ha}^{-1}, 1125 \mathrm{~kg} \mathrm{ha}^{-1}$, and $2250 \mathrm{~kg} \mathrm{ha}^{-1}$, respectively. Other agronomic management techniques were similar among plantations and included pruning, tilling, and weeding. No fertilizer or organic inputs were applied in the forest. More detailed information about the study sites were reported in the former research Yan et al. 2018.

\section{Soil sampling and analyses}

The tea plantations were $>1000 \mathrm{~m}^{2}$, and four plots of approximately $250 \mathrm{~m}^{2}$ were established in each plantation. Soil samples were collected from each plot in October 2017. Sampling was conducted in 10 $\mathrm{cm}$ increments at depths of $0-20 \mathrm{~cm}$, and in $20 \mathrm{~cm}$ increments at depths of $40-60 \mathrm{~cm}$. Each composite samples consisted from ten points in each plot, and completely mixed to form a homogenized sample. The fresh soil samples were passed through a $5 \mathrm{~mm}$ sieve, and plant residues, roots, and stones were removed. Then soil samples were air-dried and passed through a $2 \mathrm{~mm}$ sieve for physicochemical analyses.

We extracted soil samples using $0.1 \mathrm{~mol} \mathrm{~L}^{-1} \mathrm{KCl}_{2}$, and measured $\mathrm{NO}_{3}{ }^{-}$and $\mathrm{NH}_{4}{ }^{+}$in the extracts using continuous flow analysis (TRAACS 2000; Seal Analysis, Mequon, WI, USA). Soil pH was measured in pastes of 1:1 (w/v) soil:distilled water mixture with an ORION 3 STAR pH meter (Thermo Ltd., USA). Soil 
organic C (SOC) and total soil N concentrations (TN) were measured using a Vario Max CN Analyzer (Elementar Analysensystem GmbH, Langenselbold, Germany). Available phosphorus (AP) and potassium (AK) were extracted using the Mehlich 3 method, and measured using inductively coupled plasma atomic emission spectroscopy (ICP-AES).

The soil fertility index (SFI), evaluated based on the soil management assessment framework (SMAF), was used as a quantitative index to evaluate soil fertility as previously described (Andrews et al., 2004). The SMAF comprises three basic components: indicator selection, indicator interpretation, and integration into a soil quality index value (Andrews et al. 1998; 2004). Soil pH, SOC, TN, AP, and AK were selected as indicator parameters. After selecting the appropriate parameters, a factor analyses were conducted. Communality was explained by each soil parameter based on the load matrix. Each parameter was weighted by the ratio of its communality to the summed communalities of all parameters (Shukla et al. 2006). Parameters were normalized to values ranging from 0.1 to 1.0 using the standard scoring function method, which contains three types of equation (Karlen et al. 2003). The "more is better" curve equation was used when the relationship between a parameter and soil fertility was positive. Conversely, when this relationship was negative, we used the "more is worse" curve equation. Finally, the "optimum" curve equation was used in cases where the relationship between the parameter and fertility was positive up to a certain threshold, and negative thereafter. The SFI was calculated as follows:

Soil fertility index $=\sum_{i=1}^{n} W i * S i$

\section{DNA amplicon and Illumina sequencing of fungal communities}

We amplified the ITS1 region using the newly developed primers ITS1FI2, 50-GAACCWGCGGARGGATCA30, and ITS2 (White et al. 1990). ITS1FI2 overlaps with ITS1F in six positions in proximity to the Nterminal of the 18s rRNA. We used combinatorial primer labeling to identify samples after multiplex sequencing. Amplification was conducted in a total volume of $20 \mathrm{~mL}$ using $50 \mathrm{ng}$ DNA, $4 \mathrm{~mL}$ HOT MOLPol BlendMaster Mix (Molegene, Germany), and $0.5 \mathrm{mM}$ each of the forward and reverse primers. PCR conditions were $5 \mathrm{~min}$ at $95^{\circ} \mathrm{C}$, followed by 35 cycles of $30 \mathrm{~s}$ at $95^{\circ} \mathrm{C}, 30 \mathrm{~s}$ at $53^{\circ} \mathrm{C}$, and $50 \mathrm{~s}$ at $72^{\circ} \mathrm{C}$. PCR was repeated three times, with an annealing temperature of $53^{\circ} \mathrm{C}$. Final elongation was conducted at $72^{\circ} \mathrm{C}$ for $5 \mathrm{~min}$. Amplicons from the five parallel PCR runs $\left(3 \times 53^{\circ} \mathrm{C}\right)$ were individually labeled to estimate the effects of annealing temperatures and repeated PCR runs on richness recovery. Purification was achieved using Agencourt AMPure XP SPRI magnetic beads. We normalized PCR products after quantifying them using a Qubit 2.0 Fluorometer (Invitrogen, Carlsbad, CA, USA), and a QubitdsDNA HS Assay Kit (Invitrogen). Products were pooled following normalization. Paired-end sequencing (2 × 150 bp) 
was conducted on an Illumina MiSeq sequencer (Illumina, San Diego, CA, USA) at the Research and Testing Laboratory, USA.

\section{Bioinformatics analyses}

Due to the large number of reads, and the even larger number of base calls per sequencing run, the total number of noisy reads may be quite substantial. To determine true diversity, it is critical to separate good reads from those that contain noise introduced by the experimental procedures. The Research and Testing Laboratory analysis pipeline attempts to correct this issue by denoising entire regions of data prior to performing any other steps in the pipeline. Noise reduction was performed using Denoiser 0.851 (Reeder and Knight 2010). Chimeric sequences were detected using UCHIME (Edgar et al. 2011) and deleted. Sequences were shortened to $300 \mathrm{bp}$, and any sequences shorter than $300 \mathrm{bp}$ were removed. Sequences were independently clustered using USEARCH (Edgar 2010) at 97\% similarity. To determine the identity of each remaining sequence, sequence quality was determined and demultiplexed using the denoised data. Then these sequences were clustered into operational taxonomic units (OTUs) using the UPARSE algorithm. The centroid sequence from each cluster was run against either the USEARCH global alignment algorithm or against high-quality sequences derived from the NCBI database (Pruitt et al. 2014). The output was analyzed using an internally developed Python program that assigns taxonomic information to each sequence and then computes and writes the final analysis files.

Fungal OTUs were assigned to functional groups by comparison to the FUNGuild 1.0 database (Nguyen et al. 2016; Yang et al. 2017). Assignment to functional guilds was conducted at the genus level, and only assignments with confidence levels of "highly probable" or "probable" were retained for analyses. Approximately $60 \%$ of the OTUs were matched to a functional guild. The relative abundance of each functional group was equal to the sum of the relative abundance of all OTUs in the group (Eldridge and Delgado-Baquerizo 2018). The Shannon diversity of functional groups was calculated using the phyloseq package (McMurdie and Holmes 2013) in R.

\section{Statistical analyses}

All datasets were rarefied to 6341 per sample, using the "rarefy" function in the R package vegan, to reduce differences in sequencing depth. We calculated OTU richness using the "diversity" function in vegan and standardized richness using the "scale" function. Community composition was analyzed using global nonmetric multidimensional scaling. Nonmetric multidimensional scaling (NMDS), based on the Bray-Curtis distances of the sequencing data and generated using vegan, was used to assess community composition along the soil profile, as well as the correlation between community structure and environmental factors (i.e., soil properties, plant richness, and diversity). Two-way ANOVA was used to evaluate the effects of fertilizer and forest type on soil chemical properties. One-way ANOVA was used to evaluate the effects of fertilizer on specific microbial groups (ectomycorrhizal, saprotrophic, and arbuscular mycorrhizal fungi biomass), as well as diversity and richness of different trophic strategies across all forest sites and the effects of forest type on plant diversity and richness. Permutational 
multivariate analyses of variance (PERMANOVA) was used to determine the effects of fertilizer and forest type on community composition (OTUs). All statistical analyses were conducted in R v.3.4.3.

\section{Results}

\section{Fungal diversity}

Average Shannon diversity of fungal communities in the tea plantations ranged from 4.2 to 5.0 , and species richness ranged from 1200 to 1500 . Fertility had no significant effects on diversity in the soil profile, either between tea plantations and forest or among fertilizer input levels (Fig. 1). However, diversity in topsoil $(0-20 \mathrm{~cm})$ and subsoils $(20-60 \mathrm{~cm})$ exhibited opposite responses to soil fertility (Fig. 1). Diversity was similar between the low input plantation and the forest. As fertility of plantation soils increased, fungal diversity increased in the topsoil relative to the subsoils. The magnitude of reductions in diversity between topsoil and subsoils increased significantly in moderate and high input treatments (Fig. 1). Correlation analyses indicated an interactive effect between soil depth and fertilizer input on fungal diversity (Fig. 1). In the topsoil $(0-10 \mathrm{~cm})$, fungal diversity increased with $\mathrm{SFI}(\mathrm{R}=0.49, p=0.05)$. Diversity was similar under different fertilizer inputs at depths of $10-20 \mathrm{~cm}$ and $40-60 \mathrm{~cm}(\mathrm{R}=0.12, p=$ $0.66, R=0.27, p=0.32)$. In contrast to topsoil, diversity at $20-40 \mathrm{~cm}$ was negatively associated with SFI $(\mathrm{R}=-0.23, p=0.04)$ (Fig. 1).

\section{Fungal community composition}

At the genus level, soil fungal communities consisted primarily of taxa in the class Saitozyma, which accounted for an average relative abundance of $30 \%$ of the sequences from the soils, followed by Mortierella (20\%) and Pseudogymnoascus (10\%) (Fig. 2). The relative abundance of Pseudogymnoascus and Umbelopsis increased in plantation soils compared to forest soils, whereas Solicoccozyma and Trichoderma had higher relative abundance in the forest (Fig. 2). In particular, the relative abundance of Pseudogymnoascus in the plantations was higher under moderate and high fertilizer inputs, while Mortierella exhibited the opposite pattern (Fig. 2). In contrast to the dominant fungal groups, the richness of minor groups (accounting for approximately $20 \%$ of the total fungal community) increased in the subsoils, particularly under higher fertilizer inputs (Fig. 2). Heat map analyses were used to determine whether fungal species increased or decreased between land-use types and fertility (Fig. S1). The fungal community in forest sites was dominated by Mortierella, whereas plantation soils were dominated by Leucoosporidum (Fig. S1). Among samples from all sites, abundant fungal groups (shown in deep red) commonly occurred in topsoil $(0-20 \mathrm{~cm})$ and varied with fertilizer input level but did not exhibit general patterns (Fig. S1). For example, Richenella and Fusarium dominated in low input soils, Phoma in moderate input soils, and Oidoma in the highest input soils. Genetic distances indicate that as fertilizer inputs increase, fungal communities in the plantations approach those of the forest soils (Fig. S1).

NMDS ordination plots based on the Bray-Curtis distance metric showed that community composition differed significantly among fertilizer input treatments (Bray-Curtis dissimilarity: PERMANOVA: $\mathrm{R}^{2}=0.51$, 
$p=0.001$ ) (Fig. 2c, d). Soil chemical properties (fertilizer effects) explained approximately $40 \%$ of the variation in fungal community composition, while vegetation and soil layers explained an additional $10 \%$, but the interactions between the two factors explained more than $50 \%$ of fungal variation (Fig. $2 \mathrm{c}$ ). Model selection indicated that fertilizer, soil layer, C, P, and N produced best model (AIC $=814.3 p=0.001)$ (Table 1).

\section{Table 1}

Indicator analysis figured out the factors combination to explain the variations of fungal communities. Layer: soil layers, Veg: vegetation types, CA: soil total Ca, MG: soil total Mg, P, N, C:

soil total P, N, C, SFI: soil fertility index; (d) conrreation between SFI and soil fungal diversity (shannon index).

\begin{tabular}{|c|c|c|c|c|}
\hline Factor combinations & Df & Variance & $\mathbf{F}$ & $\operatorname{Pr}(>\mathrm{F})$ \\
\hline $\mathrm{K}+\mathrm{P}+\mathrm{C}+\mathrm{N}+\mathrm{CA}+\mathrm{MG}+\mathrm{pH}$ & 7 & 885.1 & 1.772 & $0.001 * * \star$ \\
\hline Veg + Layer & 2 & 454.7 & 3.133 & $0.001 * * \star$ \\
\hline $\mathrm{K}+\mathrm{P}+\mathrm{C}+\mathrm{N}+\mathrm{CA}+\mathrm{MG}+\mathrm{pH}+\mathrm{Veg}+$ Layer & 9 & 1099.2 & 1.7439 & $0.001 * * *$ \\
\hline $\mathrm{K}+\mathrm{P}+\mathrm{C}+\mathrm{N}+\mathrm{CA}+\mathrm{MG}+\mathrm{pH}+$ Condition (Veg + Layer) & 7 & 644.5 & 1.3147 & $0.001 * \star \star$ \\
\hline Veg + Layer + Condition $(\mathrm{K}+\mathrm{P}+\mathrm{C}+\mathrm{N}+\mathrm{CA}+\mathrm{MG}+\mathrm{pH})$ & 2 & 214.1 & 1.5285 & $0.001 * * *$ \\
\hline
\end{tabular}

\section{Functional guild composition}

With respect to the functional guilds identified by comparison to FUNGuild, ectomycorrhizal fungi, endophytic fungi, plant pathogens, soil saprotrophs, and animal and fungal parasites accounted for approximately $40 \%$ of the sequences, whereas the function of the other $60 \%$ was unclear. Soil saprotrophs, and parasites were the dominant functional groups, accounting for approximately $10 \%, 15 \%$, and $15 \%$, respectively (Fig. $2 \mathrm{~b}$ ). The relative abundance of soil saprotrophs increased with fertilizer inputs throughout the soil profile, particularly at depths of $0-10 \mathrm{~cm}$ (topsoil) and 20-40 cm (subsoil) (Fig. 2b). Most of these additional saprotrophs represented saprotrophs that also exhibit pathogenic traits (Fig. S2). Clavarioids and Gasteroids were enriched in moderate fertilizer input plots (Fig. S2). Microfungus yeasts were dominant in low input plots (Fig. S2), and facultative yeast microfungi were commonly found in higher input plots (Fig. S2). Plant pathogens were distributed in deeper layers $(40-60 \mathrm{~cm})$, and increased slightly with increased fertilizer inputs (Fig. S2).

\section{Fungal co-occurrence networks}

Co-occurrence network analyses suggested that fertilizer inputs simplified the soil fungal network structure in deeper soil layers (Fig. 3). By contrast, no significant differences were found among layers within fertility treatments. High network complexity was observed at depths of $0-10 \mathrm{~cm}$, reflecting increased niche links (Fig. 3) and indicating that the input treatments underlie the higher network complexity observed at these depths. Conversely, networks were much simpler in deeper soil layers within input treatments. Samples collected at depths of $10-20 \mathrm{~cm}$ and $20-40 \mathrm{~cm}$ were similar with respect to network connections (Fig. 3). The deepest layer $(40-60 \mathrm{~cm})$ had fewer interactions than shallower soils 
layers $(0-40 \mathrm{~cm})$ (Fig. 3). Complex networks suggests that most microbial species share similar ecological niches, which are shaped by environmental factors. Simple networks, by contrast, suggest that microbial species have variable ecological niches that are shaped by microbial interactions.

\section{Discussion}

\section{Loss of fungal diversity with fertilizer inputs between topsoil and subsoils}

Soil fertility in tea plantations resulted in a significant reduction in fungal diversity in subsoils but a slight increase in diversity in topsoil (Fig. 1). Ji et al. (2020) investigated fungal diversity in tea plantations across China, similar to our study, and suggested that fertilizer inputs significantly increase fungal diversity in topsoil. Such improvements may be explained by substrate availability for decomposers: enrichment of available $\mathrm{C}$ and $\mathrm{N}$ will benefit saprotrophic fungi concentrated in topsoil (Sterkenburg et al. 2015). Saprotrophic fungi were dominant in topsoil, where they were sustained by $C$ and $N$ from organic matter decomposition, but were less active in tea plantations due to resource limitations (Klaubauf et al. 2010). Fungal communities in subsoils have recently attracted increasing attention, as they typically have either positive (e.g., mycorrhizal fungi) or negative (e.g., pathogenetic fungi) effects on plant growth (Yadav et al. 2015). In contrast to topsoil fungi, subsoil fungi obtain $C$ primarily from plants, and nutrients (e.g., N, P) from the decomposition of inorganic matter (Sosa-Hernández et al. 2018). Therefore, plant C allocation and soil environmental conditions critically impact substrate availability and utilization for fungal species in subsoils (Zhang et al. 2016). Fertilization reduces plant $C$ allocation, consequently reducing mycorrhizal fungi in agricultural areas (Dai et al. 2013). Other saprophytic fungi in subsoils cannot easily obtain additional $\mathrm{C}$ or nutrients from organic inputs, but may be directly affected by changes in soil pH that result from organic $\mathrm{C}$ inputs (Table 1). Low pH reduces the capacity of saprophytic fungi to decompose soil organic matter through enzyme activity, resulting in lower diversity and loss of some species (Wardle et al. 2004).

\section{Effects of plantation management on soil fungi depend on functional guilds}

Both land-use change and fertilization altered the dominant soil fungi in tea plantations, not only at the species level but also with respect to functional guilds. When forests are converted into tea plantations, the primary change in fungal groups is the loss of root symbionts of woody plants. Development of tea plantations is associated with reduced litter inputs and increased fertilization, which mostly affect saprotrophic fungi (Fig. 2). The loss of mycorrhizal fungal diversity was clearly a result of losses of hostspecific taxa due to declines in plant diversity (Shi et al. 2014). Mycorrhizal fungi in the tea plantations also declined slightly with fertilization, which may be the result of changes in plant $\mathrm{C}$ allocation (Shi et al. 2019b). Tea plantations in the study area established on forest soils, and whereas land-use changes involve significant losses of plant diversity, soil physical and chemical properties remain relatively unchanged by fertilization (Gu et al. 2019). However, high levels of fertilization increase differences 
between topsoil and subsoil fungi. In addition, it appears that high inputs shift the fungal community from recalcitrant $C$ decomposers toward labile $C$ decomposers (Rovira and Vallejo 2002). Laboratory experiments have shown that labile $\mathrm{C}$ inputs $\mathrm{r}$ educe the efficiency of microbial $\mathrm{C}$ use and simplify community composition (Kallenbach et al. 2015). With the loss of mycorrhizal fungi in the subsoil following fertilization, some saprotrophic opportunities disappear due to additional substrate availability from decomposition processes in topsoil (Dannenmann et al. 2009). However, these species still comprise a small fraction of the total fungal community.

\section{Responses of soil fungal assembly processes to fertilization varied by soil layer}

Two theories have been proposed to explain soil fungal assembly processes under natural conditions: ecological niche selection and neutral theory. Initial processes generally result in simpler co-occurrence networks, while later processes promote complex networks (Weiher et al. 2011). With increased fertilization, the fungal community exhibited more complex interactions in the topsoil, but fewer interactions in subsoils (Fig. 3). The complex interactions suggest that a dominant environmental factor was limiting the niches of fungal species; in our study this factor was fertilizer inputs. Fertilizer inputs created new niches with respect to nutrients and C conditions, as suggested in several studies (Ahmed et al. 2019). In the topsoil, fertilization pushed fungal community assembly processes toward more connectivity and increasingly complex interactions, suggesting that the available $C$ in fertilizer may act as an important regulator, as proposed in previous studies (Ahmed et al. 2018). In contrast to patterns in the topsoil, assembly processes in the subsoil responded to fertilization by shifting toward decreased and fewer connections, suggesting that they were driven by microbial interactions rather than environmental stress (Rosado and Holder 2013). These microbial interactions located among mycorrhizal fungi, saprotrophic fungi, and pathogenetic fungi due to their substrate's competitions.

\section{Appropriate fertilization management improves recovery of microbial activity}

Soil fertility is closely linked to soil organic matter, which in turn is influenced by inputs such as biomass management and microbial activity, which decrease following conversion of forests to tea plantations (Moran 2014). To address this problem, increased organic $C$ inputs have been used in restoration to prime microbial activity. Our results confirm that saprotrophic fungi become increasingly similar with those in forests as organic matter inputs increase (Shi et al. 2019a). Our results also confirm that plant litter inputs were the driver of fungal diversity and functional recovery, due to substrate limitations (Zu et al. 2019). Similar results were reported in a restoration study that used organic matter inputs (Sun et al. 2016). However, heavy fertilization leads to a loss of fungi diversity in the subsoil, slowing $C$ decomposition and nutrient cycles, and consequently negatively impacting soil health and plant growth (Dang 2005). In addition, certain pathogenic fungi appeared throughout the soil profile under high fertilizer inputs, potentially damaging soil health in tea plantations. Similar results were found under higher disturbance treatments (Shi et al. 2019a). These results suggest that developing effective 
fertilization practices will require additional studies targeted at promoting the recovery of microbial activity.

\section{Conclusion}

We investigated soil fungi in vertical soil profiles from tea plantations with different fertilizer input levels, as well as a nearby forest, to evaluate the effects of land-use change and fertilization on fungal diversity and function. Conversion of forests to plantations has led to changes in the dominant fungal groups. As fertilizer inputs have increased in plantations, higher soil fertility has resulted in significant losses of fungal diversity in subsoils but slight increases in topsoil. Fungal network complexity has been enhanced in topsoils under conditions of increased fertility but diminished in subsoils, suggesting increased selection power throughout the soil profile.

\section{Declarations}

\section{Acknowledgements}

This work was financially supported by the National Natural Science Foundation of China (42007096), the National Key R\&D Program of China 2017YFE0107500, the Science and Technology Innovation Project of the Chinese Academy of Agricultural Sciences (CAAS-ASTIP-2014-TRICAAS)

\section{Funding:}

The National Natural Science Foundation of China (42007096), Peng Yan

The National Key R\&D Program of China 2017YFE0107500, Wenyan Han

\section{Conflicts of interest}

The authors declare no conflict of interest.

Availability of data and material: Not applicable

Code availability: Not applicable

Authors' contributions:

Peng Yan, Jianyu Fu and Wen-Yan Han conceived and designed the research; Zhenhao Zou, Chen Shen, Xin Li, Liping Zhang, Lan Zhang, Lichao Fan and Chunwang Dong performed the experiments and analyzed the data; Peng Yan, and Lingling Shi discussed the data; Lingling Shi wrote the manuscript with the contributions from the other authors.

\section{References}


1. Ahmed MA, Banfield CC, Sanaullah M, Gunina A, Dippold MA (2017) Utilisation of mucilage C by microbial communities under drought. Biology \& Fertility of Soils. 54:83-94

2. Ahmed W, Huang J, Liu K, Qaswar M, Zhang H (2019) Changes in phosphorus fractions associated with soil chemical properties under long-term organic and inorganic fertilization in paddy soils of southern China. PLoS One 14:e0216881

3. Baar J, Horton TR, Kretzer AM, Bruns TD (1999) Mycorrhizal colonization of Pinus muricata from resistant propagules after a stand-replacing wildfire. NEW Phytol 143:409-418

4. Baath $\mathrm{E}$, Anderson TH (2003) Comparison of soil fungal/bacterial ratios in a $\mathrm{pH}$ gradient using physiological and PLFA-based techniques. SOIL Biol Biochem 35:955-963

5. Blagodatskaya E, Kuzyakov Y (2008) Mechanisms of real and apparent priming effects and their dependence on soil microbial biomass and community structure: Critical review. Biol. Fertil. Soils 45:115-131

6. Bonfante P (2018) The future has roots in the past: the ideas and scientists that shaped mycorrhizal research. New Phytol 220:982-995

7. Dai M, Bainard LD, Hamel C, Gan Y, Lynch D (2013) Impact of land use on arbuscular mycorrhizal fungal communities in rural Canada. Applied \& Environmental Microbiology 79, 6719-6729

8. Dang MV (2005) Soil-plant nutrient balance of tea crops in the northern mountainous region, Vietnam. Agric Ecosyst Environ 105:413-418

9. Dannenmann, Simon, Gasche, Holst, Naumann, PS, Koegel-Knabner, Knicker, Mayer, Schloter (2009) Tree girdling provides insight on the role of labile carbon in nitrogen partitioning between soil microorganisms and adult European beech. SOIL BIOL BIOCHEM 2009,41(8), 1622-1631

10. Dumbrell AJ, Nelson M, Helgason T, Dytham C, Fitter AH (2010冈 Relative roles of niche and neutral processes in structuring a soil microbial community. The ISME Journal 4:337-345

11. García-Orenes F, Roldán A, Morugán-Coronado A, Linares C, Cerdà A, Caravaca F $₫ 2016 \bigotimes$ Organic Fertilization in Traditional Mediterranean Grapevine Orchards Mediates Changes in Soil Microbial Community Structure and Enhances Soil Fertility. Land Degradation \& Development, 1622-1628

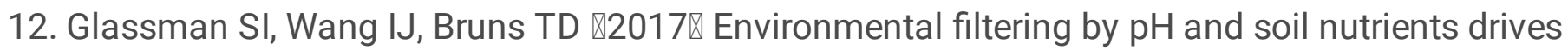
community assembly in fungi at fine spatial scales. Mol Ecol 26:6960-6973.

13. Goldfarb KC, Karaoz U, Hanson CA, Santee CA, Bradford MA $₫ 2011 \otimes$ Differential Growth Responses of Soil Bacterial Taxa to Carbon Substrates of Varying Chemical Recalcitrance. Frontiers in Microbiology 2, 94.

14. Griffin DM $\otimes 1963 \rrbracket$ Soil moisture and the ecology of soil fungi. Biol Rev 38:141-166

15. Gu S, Hu Q, Cheng Y, Bai L, Liu Z, Xiao W, Gong Z, Wu Y, Feng K, Deng Y, Tan L (2019) Application of organic fertilizer improves microbial community diversity and alters microbial network structure in tea (Camellia sinensis) plantation soils. Soil and Tillage Research 195, 104356

16. J Cira N, Pearce MT, Quake SR (2018) Neutral and selective dynamics in a synthetic microbial community. Proc Natl Acad Sci U S A 115:E9842-E9848. 
17. Ji L, Ni K, Wu Z, Zhang J, Yi X, Yang X, Ling N, You Z, Guo S, Ruan J (2020) Effect of organic substitution rates on soil quality and fungal community composition in a tea plantation with longterm fertilization. Biology and Fertility of Soils 56, 633-646.

18. Kallenbach CM, Grandy AS, Frey SD, Diefendorf AF (2015) Microbial physiology and necromass regulate agricultural soil carbon accumulation. Soil Biol Biochem 91:279-290.

19. Klaubauf S, Inselsbacher E, Zechmeister-Boltenstern S, Wanek W, Gottsberger R, Strauss J, Gorfer M (2010) Molecular diversity of fungal communities in agricultural soils from Lower Austria. Fungal Diversity $44,65-75$.

20. Lazcano C, Gómez-Brandón M, Revilla P, Domínguez J (2013) Short-term effects of organic and inorganic fertilizers on soil microbial community structure and function: A field study with sweet corn. Biol Fertil Soils 49:723-733.

21. McGuire KL, Allison SD, Fierer N, Treseder KK (2013) Ectomycorrhizal-Dominated Boreal and Tropical Forests Have Distinct Fungal Communities, but Analogous Spatial Patterns across Soil Horizons. PLoS One 8:e68278.

22. Moran RE (2014) Growth and Yield of 'Honeycrisp' Apple Trees with Preplant Inoculation with Mycorrhizae and Soil-Incorporated Compost. J Am Pomol Soc 68:2-13

23. O'Malley MA (2008) "Everything is everywhere: but the environment selects": ubiquitous distribution and ecological determinism in microbial biogeography. Stud Hist Philos Sci Part C Stud Hist Philos Biol Biomed Sci 39:314-325.

24. Peigné J, Vian JF, Payet V, Saby NPA (2018) Soil fertility after 10 years of conservation tillage in organic farming. Soil Tillage Res 175:194-204.

25. Rosado BHP, Holder CD (2013) The significance of leaf water repellency in ecohydrological research: A review. Ecohydrology 6:150-161.

26. Rousk J, Brookes PC, Bååth E (2009) Contrasting soil pH effects on fungal and bacterial growth suggest functional redundancy in carbon mineralization. Appl Environ Microbiol 75:1589-1596.

27. Rovira P, Vallejo VR (2002) Labile and recalcitrant pools of carbon and nitrogen in organic matter decomposing at different depths in soil: An acid hydrolysis approach. Geoderma 107:109-141.

28. Shi L, Dossa G, Paudel EN, Zang H, Xu J, Harrison R (2019) Changes in fungal communities across a forest disturbance gradient.Fungal Divers 64:305-315

29. Shi L, Dossa G, Paudel EN, Zang H, Xu J, Harrison R (2019) Changes in fungal communities across a forest disturbance gradient. Appl Environ Microbiol 85:12.

30. Shi L, Feng W, Jing X, Zang H,Mortimer Peter,Zou X (2019b) Contrasting responses of soil fungal communities and soil respiration to the above- and below-ground plant $\mathrm{C}$ inputs in a subtropical forest. Eur J Soil Sci 70:ejss.12777.

31. Sosa-Hernández MA, Roy J, Hempel S, Kautz T, Köpke U, Uksa M, Schloter M, Caruso T, Rillig MC (2018) Subsoil arbuscular mycorrhizal fungal communities in arable soil differ from those in topsoil. Soil Biology and Biochemistry 117, 83-86. 
32. Sterkenburg E, Bahr A, Brandström Durling M, Clemmensen KE, Lindahl BD (2015) Changes in fungal communities along a boreal forest soil fertility gradient. New Phytol 207:1145-1158.

33. Sun R, Dsouza M, Gilbert JA, GuoX, Wang D, Guo Z, Ni Y, Chu H (2016) Fungal community composition in soils subjected to long-term chemical fertilization is most influenced by the type of organic matter. Environ Microbiol 18:5137-5150.

34. Tanjang S, Shukla AK, Arunachalam K, Arunachalam A (2009) Mineralization Dynamics of Nitrogen and Phosphorus in Areca Catechu L.-Based Traditional Agroforestry System. Commun Soil Sci Plant Anal

35. Tedersoo L, Bahram M, Cajthaml T, Põlme S., Hiiesalu I, Anslan S, Harend H, Buegger F, Pritsch K, Koricheva J, Abarenkov K (2016) Tree diversity and species identity effects on soil fungi, protists and animals are context dependent. ISME J 1-17.

36. Tedersoo L, Bahram M, Polme S, Koljalg U, Yorou NS, Wijesundera R, Villarreal Ruiz L, VascoPalacios AM, Thu PQ, Suija A, Smith ME, Sharp C, Saluveer E, Saitta A, Rosas M, Riit T, Ratkowsky D, Pritsch K, Poldmaa K, Piepenbring M, Phosri C, Peterson M, Parts K, Partel K, Otsing E, Nouhra E, Njouonkou AL, Nilsson RH, Morgado LN, Mayor J, May TW, Majuakim L, Lodge DJ, Lee SS, Larsson KH, Kohout P, Hosaka K, Hiiesalu I, Henkel TW, Harend H, Guo LD, Greslebin A, Grelet G, Geml J, Gates G, Dunstan W, Dunk C, Drenkhan R, Dearnaley J, De Kesel A, Dang T, Chen X, Buegger F, Brearley FQ, Bonito G, Anslan S, Abell S, Abarenkov K (2014) Fungal biogeography. Global diversity and geography of soil fungi. Science 346, 1256688.

37. Wardle DA, Bardgett RD, Klironomos JN, Setälä H, van der Putten WH, Wall DH( 2004) Ecological linkages between aboveground and belowground biota. Science 304(5677):1629-33.

38. Weiher E, Freund D,Bunton T, Stefanski A, Lee T, Bentivenga S (2011) Advances, challenges and a developing synthesis of ecological community assembly theory. Philos. Trans. R. Soc. B Biol. Sci. 366:2403-2413

39. Yadav A, Yadav K, Aggarwal A (2015) Impact of Arbuscular Mycorrhizal Fungi with Trichoderma viride and Pseudomonas fluorescens on Growth, Yield and Oil Content in Helianthus annuus L. J Essent OIL Bear PLANTS 18:444-454.

40. Yan P, Shen C, Fan LC, Li X, Zhang L, Zhang LP, Han WY (2018) Tea planting affects soil acidification and nitrogen and phosphorus distribution in soil. Agric Ecosyst Environ 254:20-25.

41. Zhang K, Lin S, Ji Y, Yang C, Wang X, Yang C, Wang H, Jiang H, Harrison RD, Yu DW( 2016) Plant diversity accurately predicts insect diversity in two tropical landscapes. Mol. Ecol 25(17):4407-19.

42. Zu Y, Ping Y, Mu L, Yang, $T(2019)$ The diversity of arbuscular mycorrhizal fungi of Rosa acicularis 'Luhe' in saline areas. J For Res 30:1507-1512.

\section{Figures}




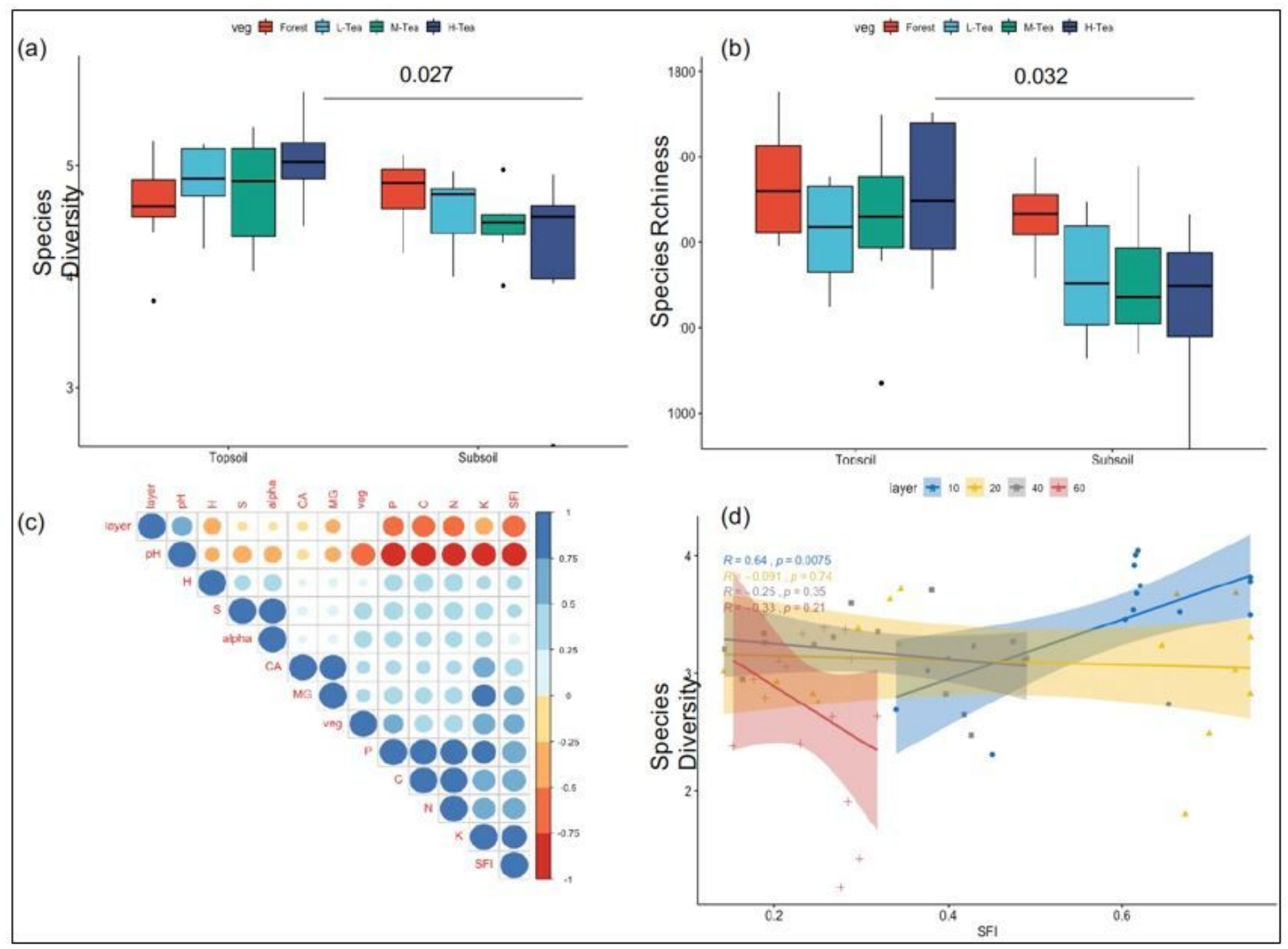

\section{Figure 1}

Fungal diversity (a) and richness (b) in topsoil and subsoil in forests compare to tea plantations under high, low, and moderate fertilizer inputs. (c) the correlation between fungal diversity indexes with environmental factors. Layer: soil layers, $\mathrm{H}$ : fungal Shannon diversity, S: species richness, apha: apha diversity, veg: vegetation types, CA: soil total Ca, MG: soil total Mg, P, N, C: soil total P, N, C, SFI: soil fertility index; (d) conrreation between SFI and soil fungal diversity (shannon index). 


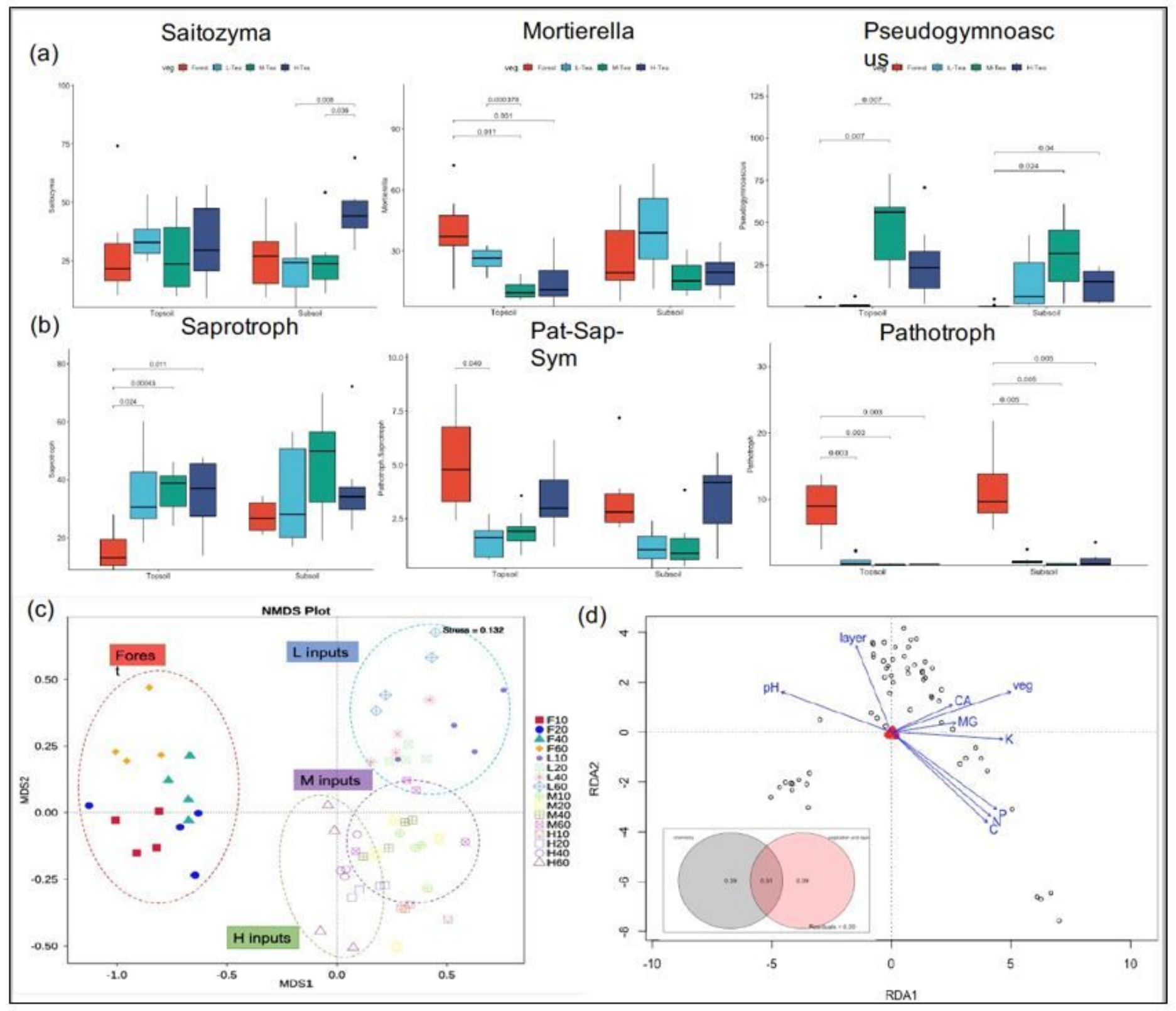

Figure 2

Dominate fungal genus (a) and functional guilds (b) in topsoil and subsoil in forests compare to tea plantations under high, low, and moderate fertilizer inputs. (c) NMDS plot showed that fungal communities were varied between forest and tea plantation. (d) RDA analysis the correlation between fungal diversity indexes with environmental factors. Layer: soil layers, $\mathrm{H}$ : fungal Shannon diversity, S: species richness, apha: apha diversity, veg: vegetation types, CA: soil total Ca, MG: soil total Mg, P, N, C: soil total P, N, C 

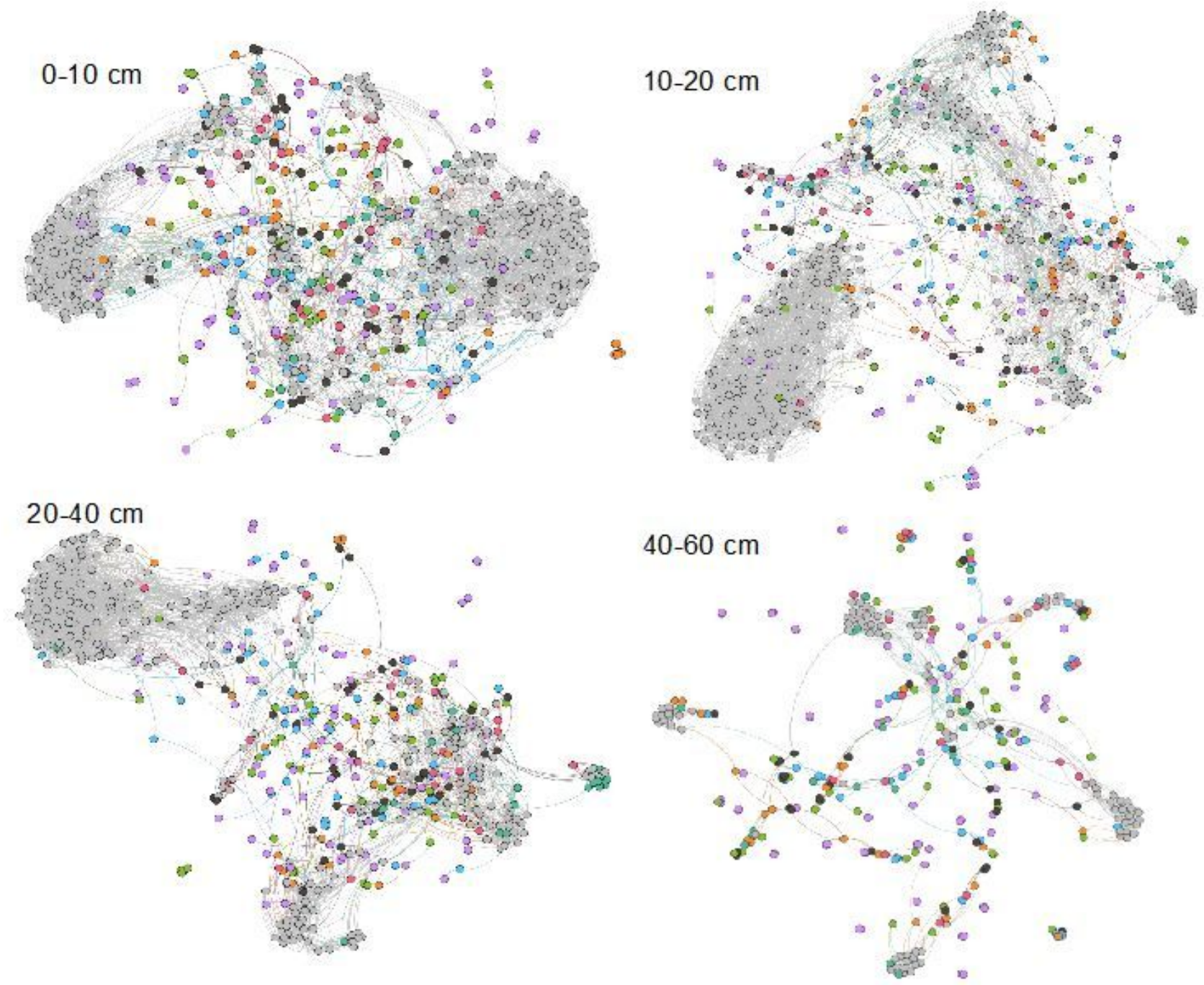

Figure 3

Co-occurrence networks of fungal communities at 14 studied sites with different fertility. Networks are randomly colored by modules.

\section{Supplementary Files}

This is a list of supplementary files associated with this preprint. Click to download.

- FigSupplementalfigures.docx 